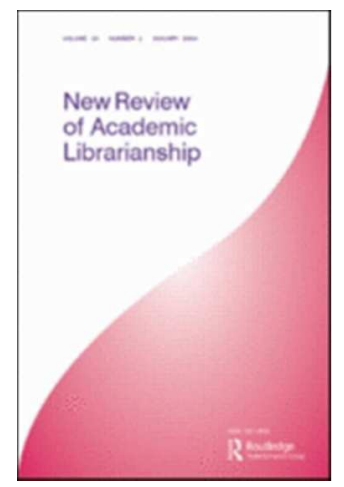

\title{
Communicating the open access message: a case study from Ireland.
}

\begin{tabular}{|r|l|}
\hline Journal: & New Review of Academic Librarianship \\
\hline Manuscript ID & Draft \\
\hline Manuscript Type: & Original Article \\
\hline Keywords: & $\begin{array}{l}\text { Institutional repository, Open access publishing, Scolarly communication, } \\
\text { University libraries, Marketing }\end{array}$ \\
\hline \multicolumn{2}{|c}{} \\
\hline
\end{tabular}

SCHOLARONE ${ }^{m}$

Manuscripts

URL: http://mc.manuscriptcentral.com/racl Email: j.g.walton@lboro.ac.uk 


\title{
Communicating the open access message: a case study from Ireland
}

\begin{abstract}
Since 2009, Open Access (OA) Week has been celebrated worldwide in October each year. It is an opportunity for librarians to engage with the research community, and demonstrate the value that they bring to their organisations in the area of disseminating scholarly output. Although thousands of events have been held since the inception of OA Week, little research has been carried out into the impact of these events. The article presents a review of the literature on OA Week and evaluates the effectiveness of three events held during OA Week 2015 in Ireland through the use of statistics and a survey. The three events held during OA Week 2015 in Ireland that were evaluated include: a seminar run by Repository Network Ireland (RNI), a D.E.A.R. (Drop Everything And Read) campaign using OA materials organised by Dr. Steevens' Library and a collaborative OA seminar between Dr. Steevens' Library and Dublin Institute of Technology (DIT) libraries. The author concludes that a collaborative approach to planning and managing OA week between librarians from academic and other sectors can have tangible benefits both in terms of promoting OA and also promoting the role of the Librarian in the OA movement.
\end{abstract}

\section{Introduction}

The OA movement is now some 25 years old. Institutional repositories which emerged as a consequence of the OA movement are an innovative model of knowledge dissemination (Koutras \& Bottis, 2013). OA has had a profound impact which has both changed and advanced scholarly communication as predicted by observers (Lynch, $2003 \&$ Prosser, 2003). For librarians, the open access movement has led to new roles, opportunities and challenges. One of the opportunities, which may also present challenges, is collaboration. International Open Access Week, celebrated around the world in October each year since 2009, opens a window of opportunity for librarians to raise their visibility and value to key stakeholders and to their scholarly communities and to collaborate. Currently a number of countries devote a specific week to promoting all things 'library'. This is called 'National Library Week' in the US, 'Library \& Information Week' in Australia, 'National Libraries Day' in the UK, New Zealand Library Week, 'Singapore Library Week', 'South Africa Library Week', 'Library Ireland Week' etc. , International Open Access Week has some similarities and aims to increase the awareness of open access in organsations alongside promoting the value of librarians to their organisations.

OA Week varies its activities and focus each year and brings together people from different disciplines in a joint effort to progress scholarly communication and access to knowledge. International Open Access Week has been celebrated by scientists, librarians, researchers and the publishing world since 2009. It came about because of a vision by the Right to Research Coalition, Public Library of Science (PLoS), Students for Free Culture and Scholarly Publishing and Academic Resources Coalition (SPARC) (Hannaford, 2011) who saw early on 
the value of marking this shift in scholarship by dedicating a week to the promotion of open access.

Since 2012 a theme has been assigned to the week which has evolved over the years reflecting the maturation of the OA movement. (See Table 1).

\section{Table 1: Theme for Open Access Week 2012-2015}

The 2015 theme was 'Open for Collaboration'. Collaboration is critical to the OA movement and to librarians in particular in promoting their value.

The freely available OA Directory which is maintained by the OA community at large contains a list of events celebrating OA Week (http://oad.simmons.edu/oadwiki/Events_celebrating_Open_Access_Week). These events were aggregated by year by this author and findings show that over the 8 years that the OA Directory has been tracking events, there has been between 200 and 500 events recorded per annum. See Figure 1. Despite the number of events, there is little research which examines their impact. This article aims to address this deficit using an Irish case study.

\section{Figure 1: No. of Events during OA Week 2008-2015 based on OA Directory Data}

\section{Background/Context}

The Irish government launched a statement on OA in 2012 (Irish Universities Association, 2012), which, like many other European countries, championed the Green route to OA. Though not a formal mandate, the statement encourages authors to self-archive their published work in a repository immediately upon acceptance for publication. The statement was produced by the National Steering Group for OA in Ireland which is made up of research organisations and the main funding bodies. The OA landscape varies considerably from that in the UK where the Gold OA route has been mandated.

In Ireland, university libraries were at the forefront in establishing repositories. Special libraries were the next adopters, particularly in the health sciences. There are seven universities in Ireland and 14 Institutes of Technology, including the Dublin Institute of Technology (DIT) and seven Colleges of Education. The majority of repositories in Ireland are in the academic sector (14) with five repositories based in special libraries according to the OpenDOAR directory. The Health Service Executive (HSE) set up an open repository named 'Lenus' in 2009 (Lawton and Manning, 2014) and the Institute of Public Health in Ireland has created a portal 'The Health Well' for health data and research: this has been available since 2010. The Health Research Board operates a National Documentation Centre on Drug Use (NDC) using the ePrints platform. The Institute of Marine Science set up its DSpace repository 'OAR' in 2011 and the National Agriculture \& Food Development Authority (Teagasc) set up a DSpace repository 'T-Stór' in 2012. There is a national infrastructure for OA in Ireland, with one main central portal, which was launched by the Irish Universities Association Librarians' Group (IUALG), with government funding, in 2010. This is called 'RIAN' (the Irish word for 'Path' http://rian.ie). RIAN was initially restricted to harvesting the output of Irish university repositories. Since 2013 it has expanded to include other repositories including those from Institutes of Technology and special libraries in the area of Marine Biology, Health and Agricultural Sciences. According to the 
Directory of Open Access Repositories (OPENDOAR www.opendoar.org/) there are 19 repositories in Ireland, 16 of these are harvested by RIAN.

Collaboration between university and special libraries has been strong in the Republic of Ireland (RoI) particularly in the area of open access. A listing of some Irish collaborative OA events held between 2009-2015, that this author was involved in, is presented in Table 2.

\section{Table 2: Collaborative events held during OA Week 2009-2015}

Similar to other European countries, Ireland has a role in communicating the OA message both at domestic and European level. The European Commission (EC) as a major funder of research has a long term commitment to OA. Since 2008 the EC has required that all funded research be made OA (European Commission, 2013). This was extended to include all EU funded projects under it's latest research and innovation programme, Horizon 2020 which is making $€ 80$ billion of funding available over 7 years (2014 to 2020) (ec.europa.eu). The supporting infrastructure is known as 'OpenAIRE' (Open Access Infrastructure for Research in Europe) which aims to capture all EC funded research (Rettberg and Schmidt, 2012).

Through the European network of National Open Access Desks (NOADs), librarians have played a key role in the advocacy of OA at local and national level. In Ireland the NOAD is run by Trinity College Dublin Library.

Having an institutional or funder mandate in place for OA has been proven to have a positive effect on the growth of repositories by ensuring that repositories are populated with content by authors (Carr et al., $2006 \&$ Gargouri et al., 2012 ). However mandates alone do not guarantee success (Xia et al., 2012). Mandates need to be carefully worded, monitored for compliance and accompanied by incentives. (Pinfield et al. 29). Compliance with mandates takes time and compliance rates vary depending on the enforcement and approach taken to monitoring. For example Poynder (2008) reports that the Welcome Trust has achieved 55\% compliance while the NIH has a $75 \%$ compliance rate over four years.

While the majority of funders of research in Ireland have OA mandates according to the Sherpa Juliet directory (http://www.sherpa.ac.uk/juliet), not all Irish universities have mandates in place. Irish universities with a mandate in place are in the minority, with only two listed in the Registry of Open Access Repository Material Archiving Policies (ROARMAP http://roarmap.eprints.org/) - these are the Dublin Institute of Technology and Trinity College Dublin. Organising an event or several events during OA Week becomes even more important for those libraries with no institutional mandate in place. OA week gives libraries an opportunity to raise awareness, educate users about OA, explain the benefits of self-archiving and how to navigate copyright issues with publishers and co-authors.

There is scope to increase OA deposit into repositories through the inclusion of OA clauses in licences between libraries and publishers. A recent review found that some progress has been made in this area, notably in Germany, Sweden and Finland through consortia based licensing or national licences (Open Access Agreements and Licences Task Force, 2013). In Ireland this is an area where little progress has been made. This is partly due to the lack of national licences in the country to electronic resources and also due to a disconnect between advocates of OA and those responsible for consortia purchasing.

Three repository managers from the special library sector set up a new network in 2013 to bridge the communication gap between special and academic library repositories in Ireland. 
The three special libraries are Dr. Steevens' Library which is part of the HSE, the Marine Institute in Ireland and Teagasc the National Agriculture and Food Authority in Ireland. The network was named 'Repository Network Ireland' (RNI). The RNI was set up by repository managers who found themselves somewhat outside of the loop of academic libraries with less access to expertise and resources than available in academic libraries. It aims to bring repository managers, librarians and others together with a common goal: to progress $\mathrm{OA}$ in Ireland.

The founders of RNI recognised the need to bring librarians, students of library and information studies and other professions from different organisations together to share expertise, exchange knowledge and build alliances. RNI is a voluntary organisation and despite having no funding, has held several successful events since its inception. In keeping with the spirit of OA, RNI is managed using open platforms such as Wikispace, LinkedIn, Twitter, Gmail, Google Forms and Eventbrite software. The communication approach has been to advertise events using Library Discussion lists, Twitter, LinkedIn and broadcast emails in organisations as well as specific websites, including Open Access Ireland (http://openaccess.thehealthwell.info/). The latter is a website set up for the National Steering Group for Open Access in Ireland, hosted by the Institute of Public Health in Ireland and Northern Ireland. Speakers for events are sourced through informal connections or by direct approach to key individuals with expertise in an area of interest to the research community. To date the RNI has run two teachmeets, a seminar on copyright and collaborated with University College Cork and Teagasc in Ireland to run a European funded 'FOSTER' training event. It is a network that is independent of the Library Association of Ireland and has grown organically. RNI was started because there was an identified need for such a network that was organisation-neutral, which freed it from burdens of organisational politics and hierarchies. Attendance at all events has been strong with people travelling from many parts of Ireland and Northern Ireland.

\section{Literature Review}

This section gives a brief overview of literature relating to Open Access Week generally and specifically literature relating to collaboration on Open Access Week.

Miller et al \& Hannaford (2013) suggest that OA week is used by libraries as a way to raise awareness of OA in general and promote added-value services provided by the library e.g. access to digital scholarship, preservation and research. At a global level, the week promotes the principles of open access and has several goals according to Rygelova, raising awareness, celebrating progress, sharing experiences and Inspiring wider participation. (Rygelova, 2012). Johnson (2014) surveyed small to medium academic libraries in the US about their participation in OA week. The survey revealed that the main reason for participation was to support the library's educational outreach activities. In Canada OA week has been used to increase awareness of OA and as an opportunity to forge new partnerships, between university presses and libraries and between research offices and libraries (Argaez, 2011). Wirth (2011) found that OA week was an opportune time for Oregon State University Libraries to reach non-library members among faculty and students to inform them about OA, local initiatives, resources open to them and to highlight the contribution of the library in progressing scholarly publishing.

For some, organizing an event during OA week had the objective of dispelling any myths surrounding open access publishing and to provide accurate information from reliable sources 
including decision makers from the publishing world (Gurman and Brunner, 2015). Gauging the level of awareness about OA at the University of Wisconsin-Eau Claire prior to OA week was found by Kocken and Wical (2013) to be an effective way to plan a marketing strategy around scholarly communication and promotion of the institutional repository. OA week presents librarians with an opportunity to advance OA beyond raising awareness, as Jennifer McLennan noted in 2010 "librarians have made Open Access Week a platform for advancing specific policy changes on research and dissemination, including institution-wide commitments to open access" (Jones, Waller \& McLennan, 2010).

The literature relating to collaboration for OA week indicates that forming a collaborative partnership is a critical success factor for holding events during OA week, particularly for libraries with limited resources (Wirth, 2011 \& Miller et al, 2013). The benefits of collaboration at Oregon State University libraries included co-sponsorship, sourcing of keynote speakers, sharing resources, provision of venues and catering (Wirth, 2011). University libraries at Virginia Tech found that partnership between different libraries led to the co-creation of content including websites and promotional materials and the joint delivery of workshops on common interests including copyright and an introduction to open access. (Miller et al, 2013).

A Canadian consortium of 22 libraries, the Council of Prairie and Pacific University Libraries (COPPUL) outlined the benefits of their collaborative approach to OA Week. Benefits included the collective generation of multimedia content about OA, the 'unconference' approach which kept with the theme of OA, the sharing of resources which in turn, generated interest at local institutions and the positive results in securing renowned speakers for their events by working together (Hohner, Vanderjagt \& Kirchner, 2011).

In the Czech Republic a consortium of 12 university libraries worked with 2 special libraries - the National Technical Library and the Library of the Academy of Sciences - to organize events for OA week in 2011. They adopted a highly organized, professional and united approach to OA week. Their collaboration produced a website 'Open Access in the CR' as a national focal point for all things OA; a Facebook page Open Access CR; promotional materials; engagement with media including a TV episode on OA and joint lectures and seminars (Rygelova, 2012). They implemented a "bottom-up" coordinated approach which proved to be an effective strategy.

University of Toronto Libraries adopted a tri-campus collaborative approach to OA awareness and outreach. . Hannaford (2011) describes how a Tri-Campus Scholarly Communication Group made up of librarians from three different campuses met bi-monthly initially to focus on planning for OA week. The group shared knowledge and experience and collaborated on solutions and other outreach activities that went beyond OA week. Subsequent efforts of the group centred around establishing a robust web presence with a devoted Libguide to scholarly communication.

Key to the assessment of OA week activities is to incorporate a quality improvement process. Virginia Libraries reported that they held debriefings post OA week events. Miller et al. (2013) describe the events held during OA week in 2012-13 at Virginia Tech University Libraries. Areas marked for improvement included better documentation of events, in particular photographic documentation to be used to market future events. They decided to use other events to promote OA beyond OA Week including the Banned Books Week. For 
future OA week activities they will seek stronger partnerships within and beyond the university.

Effective communication is vital during OA week. The key communicators of the OA message are librarians, students, faculty, researchers and editors, publishers. There are different permutations of these communicators, but all are generally important to an effective knowledge exchange. Librarians may act as knowledge intermediaries or knowledge brokers in this scenario. Meyer (2010) defines knowledge brokers as "people or organizations that move knowledge around and create connections between researchers and their various audiences". Librarians facilitate the exchange of knowledge between for example students and publishers as was seen at UCLA library. For OA week, the UCLA Library's Scholarly Communication Steering Committee brought together graduate students ready to archive their electronic theses and academic and trade editors looking to publish books (Gurman et al., 2015). Other intermediaries act as knowledge brokers in university settings. The University of Sussex the use of doctoral students as intermediaries during Open Access week providing librarians with a valuable insight into the needs of researchers and enabling librarians to better align training programs to their needs (Ball, 2012).

Libraries of all types have reconfigured space to match the evolving needs of their communities. In the UK many libraries have created dedicated areas for researchers. Such spaces have effectively been used to promote awareness of OA and to host events during OA week. The University of Sussex has created such a space called the "Research Hive" which acts as a focal point during OA week and is reported to be highly successful and "a well-loved space" (Harvell and Ball, 2014).

\section{Events to promote Open Access}

There were three events in this Irish endeavour. Each is described in turn. The first event is the RNI seminar. The aim of this seminar was captured by its title "Let's talk about data, developments and collaboration". This was aligned to the theme of the 2015 OA week "Open for collaboration". The seminar created a dedicated time and place for an interested audience to discuss these three issues in the context of OA week. RNI members sourced speakers through electronic library discussion lists, LinkedIn group messages, Twitter and personal contacts. RNI members held just one teleconference and successfully organized the seminar in a matter of weeks. The venue and catering was sponsored by the Health Research Board, the main funder of health research in Ireland. The programme for the seminar was made available on the RNI communications platform Wikispace. There were ten speakers, five from academic libraries and 5 from special libraries. The event was opened by the CEO of the Health Research Board. The editor of the LAI journal 'An Leabharlann' which became $\mathrm{OA}$ in 2014 presented. One external speaker from Figshare in the UK also gave a presentation.

The next event is the DEAR OA campaign - a one day event held during OA Week - was organized by the Library Services manager of Dr. Steevens' Library who has successfully run several DEAR campaigns in 2014/15. One of these event attracted media attention from a national newspaper (Ní Bhriain, 2015). 
Dr. Steevens' Library is located in the corporate headquarters of the National Health Service in Ireland. The building houses the Health Board senior management and the offices of the various areas in the health service including public health, primary care, social care, acute hospitals, quality improvement and health and well-being. The aim of the DEAR campaign was to raise the visibility of the library and open access materials to key stakeholders in the building and to others located elsewhere in the service through the availability of reading material on the Library Blog. Material was categorized into material that could be read between 5-10 minutes and 15-20 minutes. Fifteen articles were selected for each category. The material chosen was all open access and was selected based on popular or hot topics in healthcare. Two of the articles included were made available on the library Blog and linked directly to items in the Irish health repository Lenus which is managed by Dr. Steevens' Library. This had the additional objective of directing traffic to the repository and boosting the use of OA material.

The DEAR campaign was advertised on Twitter, the Library Blog and via a broadcast email to all staff. Library staff set up a table in the staff canteen with several copies of printed open access articles with a pop-up banner for the Library and posters advertising the repository and open access. During a morning break and lunchtime, library staff were available to engage with people in the building and talk to them about open access, the repository and the DEAR campaign.

The third event was a collaborative seminar between DIT libraries and Dr. Steevens' Library. Both organisations have a joint connection. The DIT is made up of several campuses currently housed at different locations in Dublin city and its surrounds. The first phase of a new campus - on the grounds of a former psychiatric hospital - was completed in September 2015. Dr. Steevens' Library had a branch in the psychiatric hospital located on the site. The library closed in 2003 but library staff from Dr. Steevens continued outreach activities and training. In 2013 a new purpose built psychiatric centre was opened on the site of the new campus. Early in 2015 the head of DIT library services and senior staff from Dr. Steevens' Library agreed to organize a joint event during open access week. Both libraries plan to work collaboratively in the future and this event served as a starting point. As the new campus was scheduled to welcome its first students in September 2015 the venue needed to be ready and fully equipped with state of the art technology by October. A date was booked for $23^{\text {rd }}$ October during OA week. The venue chosen was a Church called St. Laurence's on DITs new campus. Five speakers were secured from different areas of the health and academic sector in Ireland, including representatives from both the HSE and DIT. The keynote speaker was Dr. Gabiel Fitzpatrick, chair of Medicins sans Frontiers in Ireland and a prominent public health specialist who has published several OA articles on his findings about Ebola during his time in Sierra Leone. The seminar was advertised via Broadcast email and posted on several library discussion lists. For the event, Dr. Steevens' Library developed a pop up Libguide on OA. Email invitations were issued to HSE staff working in the area close to the campus. Conference packs included promotional literature from both DIT and HSE libraries. Pop up banners for both libraries were displayed in the seminar venue. Eye catching helium balloons using the OA logo and the repository logo were displayed in an arch at the entrance to the venue. They had a big visual impact and were an attractive display on campus.

\section{Methodology}


There is a lack of literature that deals specifically with the assessment of OA outreach activities. A starting point for assessment of activities is to note the number of people attending $\mathrm{OA}$ events, to track repository hits and and monitor visits to library webpages containing information about OA.. (Miller et al, 2013) For both seminars a short evaluation form was included in a welcome pack for attendees. The form asked respondents to identify their profession with available choices provided as shown below:

Please choose your profession:

Librarian/Information Specialist

Manager

Academic/Researcher

Other (Please specify)

Health Professional

The evaluation form contained 5 questions. These were:

1. What was the most useful part of today's seminar?

2. What was the least useful part of today's seminar?

3. Please respond to the following statement:

\begin{tabular}{|l|c|c|c|c|c|}
\hline \multirow{2}{*}{$\begin{array}{l}\text { Today's seminar } \\
\text { increased my } \\
\text { awareness of open } \\
\text { access }\end{array}$} & $\begin{array}{l}\text { Strongly } \\
\text { Disagree }\end{array}$ & Disagree & Undecided & Agree & $\begin{array}{c}\text { Strongly } \\
\text { Agree }\end{array}$ \\
\cline { 2 - 6 } & 1 & 2 & 3 & 4 & 5 \\
\hline
\end{tabular}

4. Do you think today's seminar was effective in facilitating collaboration between different sectors of the Irish research community?

Yes $\square$ No $\square$ I'm not sure

5. Is there anything that you will do differently as a result of attending this seminar today?

Questions were deliberately kept to a minimum. It was felt this would make the process short and easy and might boost response rate. No personal information was gathered from respondents. Prior to the events, the author tested the survey with a number of librarians and sent the survey to two subject experts to review.

The same form was used for both seminars to facilitate data analysis and comparison between results. During the welcome speech at both seminars the importance of returning completed feedback forms was highlighted, both to assist with the planning of future events and to inform research into events held during Open Access Week. The author explained to all attendees that she were available after the event for any questions that participants might have. 
For the DEAR campaign, a tally was recorded of the number of articles distributed during the one day campaign. Metrics were gathered from Twitter and repository hits and downloads after the event were analysed.

\section{Results and Discussion}

\section{RNI Seminar}

There were 31 attendees at the RNI seminar. 15 responses to the evaluation were collected, representing a $48 \%$ response rate. Of these 13 were librarians or information specialists and two were researchers. This is not surprising as the target audience for the seminar was librarians.

Responses to the first question which asked "What was the most useful part of today's seminar?" were overwhelmingly positive towards the entire programme. Responses included: the range of speakers, the practical tips shared, the knowledge (particularly around Altmetrics) gained, Google Analytics, Figshare and engaging with researchers were all mentioned by the majority of respondents as being very useful.

The second question "What was the least useful part of today's seminar?" was answered with three comments. One was about the lack of a microphone making it difficult to hear speakers from the back of the room; another was a request for increased time in the schedule for networking and one respondent did not find the 'Figshare sales pitch' useful. A further three comments declared that every presentation was useful and informative.

The aim of the seminar which was to increase awareness about OA was achieved as the majority of respondents(14) to question three either agreed (10) or strongly agreed (4) that the seminar increased their awareness of open access.

Question four asked attendees whether they thought that the seminar was effective in facilitating collaboration between different sectors of the Irish research community. The additional aim of collaboration was met with the majority of respondents reporting that they felt that the seminar was effective in facilitating collaboration between different sectors of the Irish research community (9), while five were undecided and one person felt it was not effective.

Question five asked if attendees would do anything differently as a result of attending the seminar. This question elicited a total of 11 responses. The majority claimed that they intended to make some changes in their repository workflows by using tools demonstrated such as Google Analytics and Altmetrics. Other comments included the intention to introduce changes to individual workflows such as research data management and at the organizational level by collaborating more with other researchers through OA workflows. Three respondents said they would contact individual speakers afterwards for their expertise. One librarian commented that they intended to use Library Ireland Week, a designated week in November 2015 to promote OA in their organization.

There was good interaction on social media during the seminar, with a total of 33 unique tweets. 


\title{
OA DEAR Campaign
}

Statistics were noted by the Library Services manager from the one day OA DEAR campaign. A total of 173 articles were distributed during two breaks in Dr. Steevens' canteen. A breakdown of items distributed by topic is shown in Table 3. The most popular category was human resources, followed by quality care.

Table 3: Total number of articles distributed by Topic during DEAR OA Campaign

The DEAR OA campaign was advertised on the HSE Library Blog and on the international open access week website. The campaign consisted of a list of all of the links to the 5-10 minute reads and the $15+$ minute reads. Details of the quantity and length of reads is outlined in Table 4.

\section{Table 4: DEAR OA Campaign Reads Listed on Library Blog}

Besides journal articles, the reads included media items such as videos, podcasts and newspaper items. It was not possible to get accurate information about the number of downloads and hits to the Blog as Google Analytics is not set up for the Blog. However two of the reads in the Blog pointed to items in the HSE repository Lenus. Of the two OA items drawn from the repository, one received 14 downloads and the other 18 downloads. The data is represented in Figure 2.

Figure 2: Downloads and Views from the repository due to DEAR Campaign

These statistics were obtained from Google Analytics which is embedded in the Open Repository platform. The statistics represent the month of October 2015 however they were checked two working days after they were advertised on the Blog making most hits and downloads attributable to the DEAR campaign.

\begin{abstract}
A broadcast email was sent twice during the day of the campaign to all HSE staff. A tweet was sent to advertise the DEAR campaign which received 4 retweets and 2 favourites as is shown in Figure 3.
\end{abstract}

Figure 3: Tweet advertising DEAR OA Campaign

\section{Joint Seminar DIT and Dr. Steevens' Library}

There were 35 attendees at the collaborative seminar between DIT Libraries and Dr. Steevens' Library. Thirteen responses were received on the day of the seminar. The evaluation form was translated into an online form using the tool Surveymonkey and sent to attendees post event which generated an further five responses. The overall response rate was $51 \%$. The majority of responses collected were from librarians or information specialists (11), with three from researchers, one health professional and three from managers. 
The most useful part of the seminar based on the feedback to question one was the range of speakers and the practical application of OA research in healthcare. In addition the sole librarian who presented during the seminar was found by four respondents to be the most useful part of the seminar and her talk 'inspirational'.

Responses to question two indicated that there all parts of the seminar were useful.

Similar to the RNI event, one of the main aims of the seminar was to raise awareness about open access. This aim was fulfilled as all respondents to question three either agreed (9) or strongly agreed (9) that the seminar increased their awareness of open access. A secondary aim was to create an effective environment for collaboration which was also achieved according to the feedback. All respondents - except two -to question four thought that the seminar was effective in facilitating collaboration between different sectors of the Irish research community. Two responded that they were unsure if this was the case.

Answers to question five which asked attendees if they would do anything differently having attended the seminar revealed some interesting responses including ideas for future OA developments. For example, one respondent suggested that OA week in Ireland required a coordinated approach and that the OA community in Ireland should come together and collaborate on a collective week long programme of events which should be supported by all. Three respondents said they would use the HSE and DIT repositories for their research. One person said they would look into the feasibility of hosting an OA health journal. Four respondents indicated that they would promote OA more in their respective organisations.

Library staff held a debriefing session a day post seminar. Unforeseen events hampered the attendance including a national rail strike y. Forty six people registered and 35 attended.

It was agreed that overall the event was a success and that the venue provided high tech equipment including $5 \mathrm{TV}$ screens with a surround sound system. This worked well for the Youtube playlist of OA videos that was collated by the organizers and aired at the opening of the seminar and during the lunch break.

It was agreed that there was good teamwork and good collaboration between both academic and special librarians which contributed to a positive event. The addition of balloons sponsored by BioMed Central added to the celebration of OA. The overhead for the catering was approximately $€ 400$ and funded from Dr. Steevens' Library's operational budget. The repository content needed a fresh update prior to the event and that was something that would be taken into account prior to any future events. More activity on Twitter was desirable although engagement with social media at any seminar is dependent on audience participation and not all librarians, researchers and managers present at the event use Twitter. There was no funding available to record the seminar which was unfortunate as livestreaming or a recording of the presentations could have generated further interest. It was also agreed that more thought needed to be put into a target audience. More targeted marketing towards researchers and health professionals will form the basis of future events as it was agreed that promoting open access amongst a predominately librarian filled audience was partly an exercise in preaching to the converted. It is hoped to secure a speaker from mainstream OA advocates such as SPARC or OpenAIRE for 2016 events.

11

URL: http://mc.manuscriptcentral.com/racl Email: j.g.walton@lboro.ac.uk 


\section{Conclusion}

The stated aims of each OA event to increase awareness of OA and facilitate collaboration were attained and all events were deemed successful. Aims that drew upon the theme of OA week worked well. It would be of interest to follow up with those attending seminars who reported intended actions as a result of their attendance, such as the development of an OA journal for health and using Library Ireland Week to promote OA. Long term goals of OA outreach activities will be to measure event attendance over time, to share findings with others, to measure the effect of activities on open access publication within the university or organization, to see an increase in the quantity of items being populated into the repository. Ludwig (2010) has pointed out that the challenge is to move beyond policy adoption and into new areas. These areas include a scenario where the library and repository are fully integrated into the wider research management role of the university or organization. As OA gains momentum and moves into broader areas including open learning objects and as MOOCs become more widespread so too will the OA workflows of academics. This paves the way for embedded OA workflows as part of everyday academic practice.

There is a lack of engagement with the professional library associations in the area of Open Access. While the Library Association of Ireland (LAI) has an area of its website dedicated to 'Library Ireland Week' as do other similar associations including CILIP in their celebration of 'National Libraries Day', there is no equivalent for OA week. This made it difficult to highlight planned events for OA week on the LAI's website. There needs to be better engagement with professional library associations in this area.

OA week would benefit from a national approach to capitalize on maximum participation as was successfully achieved in the Czech Republic (Rygelová, 2012). Each institution, university or specialized organization needs an OA champion to drive the OA agenda. Planning for OA week outreach activities requires advance preparation and a clearly defined goal. Evaluating events and using feedback as part of a quality improvement process for future events will lead to better outcomes for communicating the OA message.

\section{References}

Argaez, Diego. (2011). "International Open Access Week." Feliciter 57.3 103-105. Ball, Joanna. (2012). "The Sussex Research Hive: Providing Peer-Led Support for Doctoral Researchers". SCONUL Focus 56:10-13.

Carr, L., Swan, A., Sale, A., Oppenheim, C., Brody, T., Hitchcock, S., ... \& Harnad, S. (2006). Repositories for institutional open access: mandated deposit policies. European Commission. (2013).“Fact sheet: Open Access in Horizon 2020”. 9. December 2013. Retrieved from:

https://ec.europa.eu/programmes/horizon2020/sites/horizon2020/files/FactSheet_Open_Acces s.pdf

Gargouri, Yassine, et al. (2012). "Testing the finch hypothesis on green OA mandate ineffectiveness." arXiv preprint arXiv:1210.8174.

Johnson, P. C. (2014). International Open Access Week at Small to Medium US Academic Libraries: The First Five Years. The Journal of Academic Librarianship, 40(6), 626-631. Kocken, Gregory J., and Stephanie H. Wical. (2013). "I've Never Heard of It Before": 
Awareness of Open Access at a Small Liberal Arts University." Behavioral \& Social Sciences Librarian 32.3 140-154.

Gurman, Diane, and Marta Brunner.(2015). "Dissertation to Book: Successful Open Access Outreach to Graduate Students." Journal of Library Innovation 6.140.

Hannaford, Julie. (2011). "Tri-Campus Teamwork: Open Access at the University of Toronto Libraries." Feliciter 57.3 94-98.

Harvell, Jane, and Joanna Ball. (2014)."Redrawing the line: challenging the publisher-library relationship." Against the Grain 18-20.

Hohner, Michael, Leah Vanderjagt, and Joy Kirchner. (2011)."Celebrating International Open Access Week the COPPUL Scholarly Communication Task Group Way." Partnership: the Canadian Journal of Library and Information Practice and Research 6.2.

Irish Government. Minister of State, Department of Enterprise, Jobs \& Innovation and Department of Education \& Skills. (2012). Government Launches National Open Access Statement - 23 Oct 2012. Irish Universities Association. Irish Universities Association, 23 Oct. 2012. Web. 4 Nov. 2015. Jones, Jamaica, Andrew Waller, and Jennifer McLennan. (2010). "Open access week: Library strategies for advancing change." Research Library Issues: A Bimonthly Report from ARL, CNI, and SPARC 270, 21-26.

Koutras, Nikos, and Maria Bottis. (2013)."Institutional repositories of open access: a paradigm of innovation and changing in educational politics." Procedia-Social and Behavioral Sciences 106, 1499-1504.

Lawton, Aoife and Padraig Manning. (2014). "Managing a national health repository." D-Lib Magazine 20.3/4.

Ludwig, Deborah. (2010). "Open access at the University of Kansas Toward a campus initiative." College \& Research Libraries News 71.7. 360-384.

Lynch, Clifford A. (2003)."Institutional repositories: essential infrastructure for scholarship in the digital age." portal: Libraries and the Academy 3.2, 327-336.

Meyer, Morgan. (2010). "The rise of the knowledge broker." Science Communication 32.1 118-127.

Miller, Rebecca K., et al. (2013). "Promoting Universal Knowledge for All: Open Access Week 2012 at Virginia Tech." Virginia Libraries April-June 31-35.

Ni Bhrian, Doireann. (2015)."Time to Drop Everything and Just Read." Irish Times [Dublin] 25 Apr. 2015: n. pag. Print.

Open Access Agreements and Licences Task Force. (2013). "Open Access Clauses in Publishers' Licences. Current State and Lessons Learned." Göttingen: Confederation of Open Access Repositories, 2013. Web. 2 Nov. 2015.

Pinfield, Stephen, et al. (2014). "Open-access repositories worldwide, 2005-2012: Past growth, current characteristics, and future possibilities." Journal of the Association for Information Science and Technology 65.12, 2404-2421.

Poynder, Richard. (2012). "Open Access Mandates: ensuring compliance." Web blog post. Open and Shut. 18 May 2012. Web. 22 Oct. 2015. http://poynder.blogspot.ie/2012/05/openaccess-mandates-ensuring.html

Prosser, David. (2003). "The next information revolution-How open access repositories and journals will transform scholarly communications." Liber Quarterly 14.1.

Rettberg, N., \& Schmidt, B. (2012). Repository communities in OpenAIRE: Experiences in building up an Open Access Infrastructure for European research. Open Repositories 2012. Rygelová, Pavla. (2012). "Open Access Week 2011 in the Czech Republic (Report)." Liber Quarterly 21.3/4, 475-481.

13

URL: http://mc.manuscriptcentral.com/racl Email: j.g.walton@lboro.ac.uk 
Wirth, Andrea A. (2011). "Incorporating Existing Library Partnerships into Open Access Week Events." Collaborative Librarianship 3.4, 197-204.

Xia, Jingfeng, et al. (2012). "A review of open access self-archiving mandate policies." portal: Libraries and the Academy 12.1, 85-102.

URL: http://mc.manuscriptcentral.com/racl Email: j.g.walton@lboro.ac.uk 


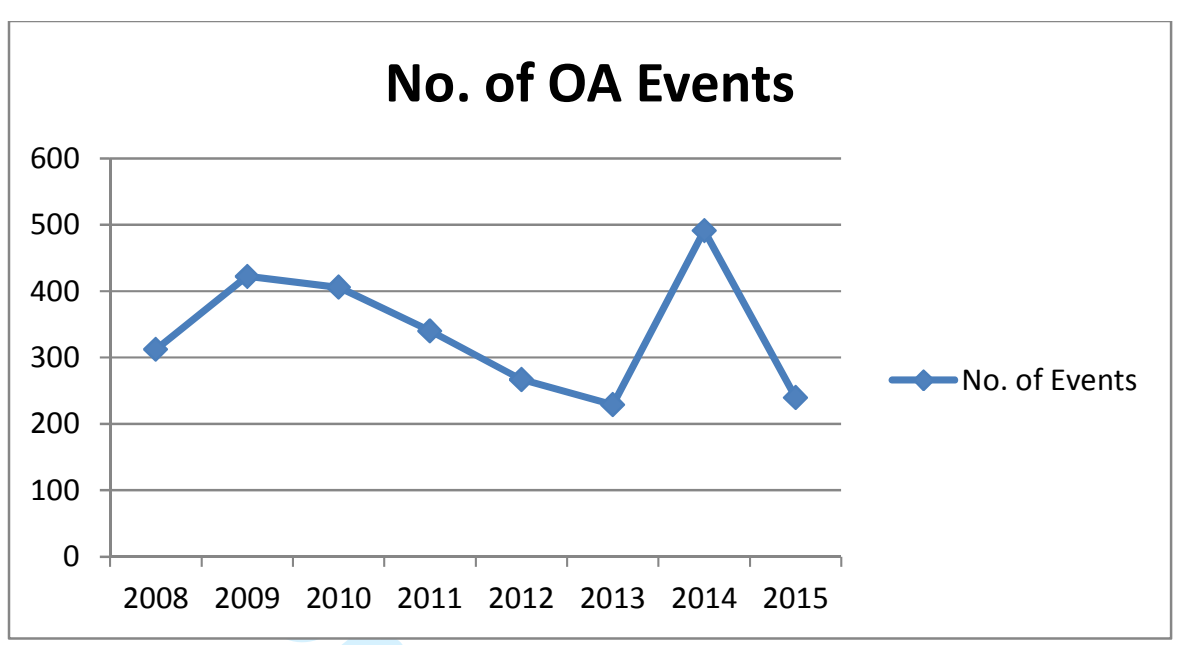

1

2

3

4

5

6

7

10

11

12

13

14

15

16

17

18

19

20

21

22

23

24

25

26

27

28

29

30

31

32

33

34

35

36

37

38

39

40

41

42

43

44

45

46

47

48

49

50

51

52

53

54

55

56

57

58

59

60

URL: http://mc.manuscriptcentral.com/racl Email: j.g.walton@lboro.ac.uk 

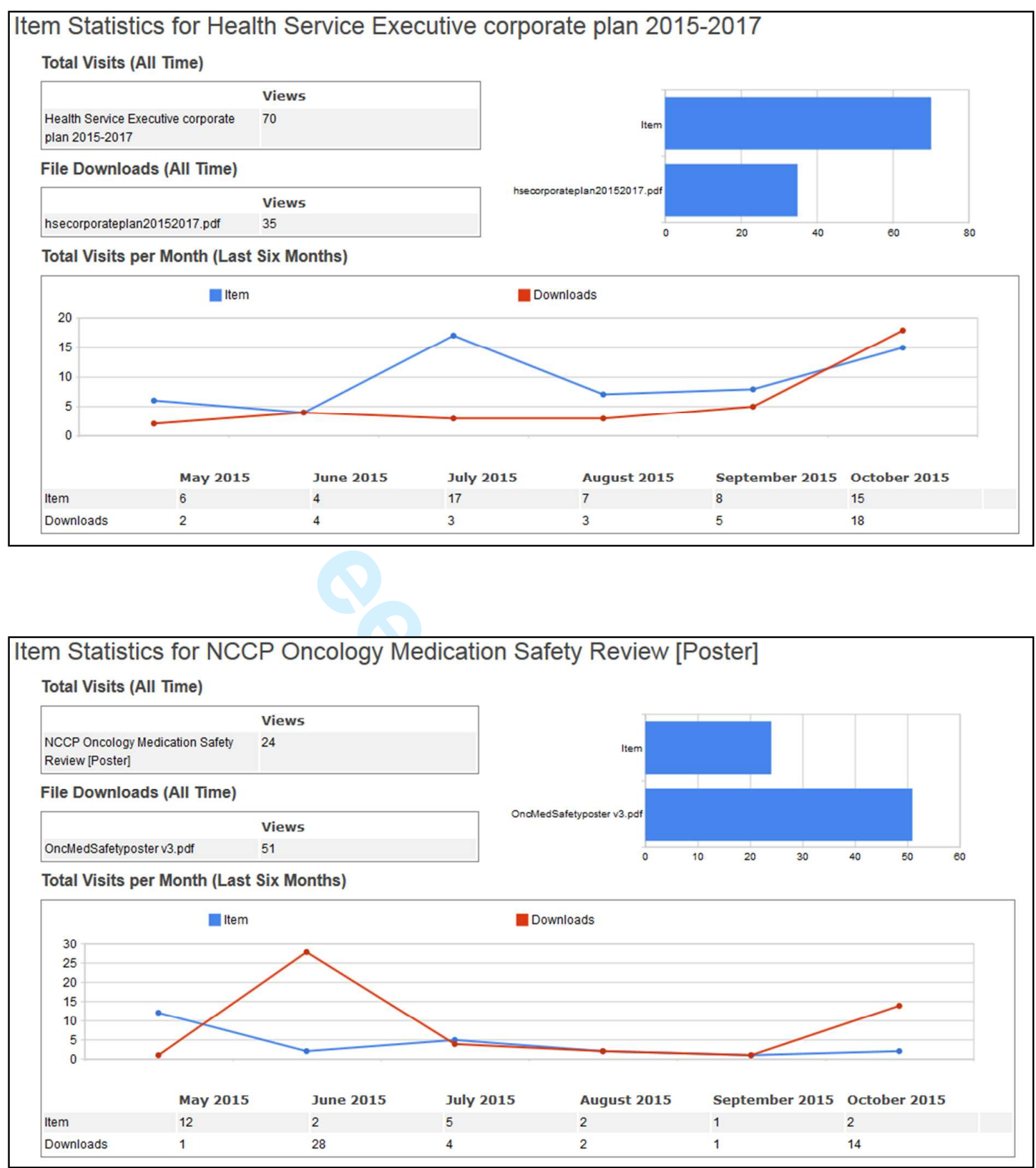

URL: http://mc.manuscriptcentral.com/racl Email: j.g.walton@lboro.ac.uk 
1

2

3

4

5

6

7

8

9

10

11

12

13

14

15

16

17

18

19

20

21

22

23

24

25

26

27

28

29

30

31

32

33

34

35

36

37

38

39

40

41

42

43

44

45

46

47

48

49

50

51

52

53

54

55

56

57

58

59

60

Dr. Steevens Library @DrSteevensLib. Oct 22

ERAR DEAR DropEverything\&Read

hselibrary.blogspot.ie When did you last read the evidence? \#openaccessweek

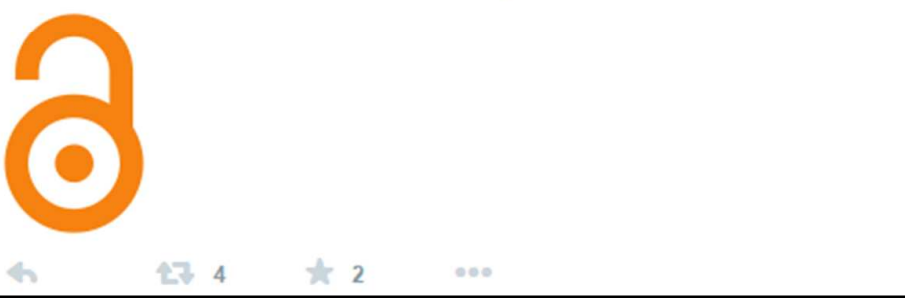

URL: http://mc.manuscriptcentral.com/racl Email: j.g.walton@lboro.ac.uk 


\begin{tabular}{|l|l|}
\hline Year & Open Access Week Theme \\
\hline 2012 & Set the Default to Open Access \\
\hline 2013 & Redefining Impact \\
\hline 2014 & Generation Open \\
\hline 2015 & Open for Collaboration \\
\hline
\end{tabular}

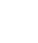

(1)




\begin{tabular}{|c|c|c|c|}
\hline Year & Event Type & Title of Event & Partners/Collaborators \\
\hline 2009 & OA Seminar & Institutional Repository Day & $\begin{array}{l}\text { Hosted by Dublin Institute of } \\
\text { Technology Libraries }\end{array}$ \\
\hline 2010 & OA Seminar & $\begin{array}{l}\text { "Open Access Publishing in } \\
\text { Health" }\end{array}$ & $\begin{array}{l}\text { Dr. Steevens' Library \& HSE Public } \\
\text { Health Department }\end{array}$ \\
\hline 2011 & OA Seminar & $\begin{array}{l}\text { "Irish Health Research: } \\
\text { Collaboration and Partnership for } \\
\text { Progress" }\end{array}$ & $\begin{array}{l}\text { Dr. Steevens' Library \& Department } \\
\text { of Health }\end{array}$ \\
\hline 2012 & Webinar & $\begin{array}{l}\text { "Open Access Research to inform } \\
\text { patient outcomes" }\end{array}$ & $\begin{array}{l}\text { Dr. Steevens' Library \& BioMed } \\
\text { Central }\end{array}$ \\
\hline 2013 & OA Seminar & $\begin{array}{l}\text { "Getting the information you } \\
\text { need; the role of Open Access in } \\
\text { supporting health and wellbeing } \\
\text { on the island of Ireland" }\end{array}$ & $\begin{array}{l}\text { Dr. Steevens' Library, Institute of } \\
\text { Public Health \& St. Patrick's } \\
\text { University Hospital }\end{array}$ \\
\hline 2014 & $\begin{array}{l}\text { OA Seminar } \\
\text { Teachmeet } \\
\text { Teachmeet }\end{array}$ & $\begin{array}{l}\text { "Open Access can help deliver a } \\
\text { Healthy Ireland" }\end{array}$ & $\begin{array}{l}\text { Dr. Steevens' Library \& Institute of } \\
\text { Public Health } \\
\text { Repository Network Ireland \& Trinity } \\
\text { College Dublin } \\
\text { Repository Network Ireland \& Trinity } \\
\text { College Dublin }\end{array}$ \\
\hline 2015 & OA Seminar & $\begin{array}{l}\text { "Open Access - Opportunities to } \\
\text { Work Together" } \\
\text { "Let's Talk About Data, } \\
\text { Developments and Collaboration" }\end{array}$ & $\begin{array}{l}\text { Dr. Steevens' Library \& Dublin } \\
\text { Institute of Technology Libraries }\end{array}$ \\
\hline
\end{tabular}




\begin{tabular}{|l|l|}
\hline TOPIC & No. of Print Articles Distributed \\
\hline Quality Care & 22 \\
\hline Human Resources & 88 \\
\hline Leadership & 5 \\
\hline Nursing & 14 \\
\hline Health \& Social Care & 3 \\
\hline Mental Health & 15 \\
\hline Allied Health & 5 \\
\hline Patient Safety & 11 \\
\hline Hospital & 10 \\
\hline Total No. of articles distributed & $\mathbf{1 7 3}$ \\
\hline
\end{tabular}


1

2

3

4

5

6

7

8

9

10

11

12

13

14

15

16

17

18

19

20

21

22

23

24

25

26

27

28

29

30

31

32

33

34

35

36

37

38

39

40

41

42

43

44

45

46

47

48

49

50

51

52

53

54

55

56

57

58

59

60

\begin{tabular}{|l|l|}
\hline URL 5 -10 minute reads & 15 URLs distributed via email \\
\hline URL 10 + minute reads & 15 URLs distributed via email \\
\hline
\end{tabular}

URL: http://mc.manuscriptcentral.com/racl Email: j.g.walton@lboro.ac.uk 